\title{
Venereophobia - a cognitive deception? Case reports with literature review
}

\author{
NA Bishurul Hafi', NA Uvais², Ettappurath N Abdul Latheef ${ }^{3}$, Muhammed Razmi T', \\ TP Afra', Silah Aysha ${ }^{4}$
}

${ }^{1}$ Consultant Dermatologist, IQRAA Center for Sexual Medicine, Kozhikkode, Kerala, India, ${ }^{2}$ Consultant Psychiatrist, IQRAA Center for Sexual Medicine, Kozhikkode, Kerala, India, ${ }^{3}$ Additional Professor, Department of Dermatology, Venereology and Leprosy, Kozhikkode Government Medical College, Kerala, India, ${ }^{4}$ House Surgeon, Kozhikkode Medical College, Kerala, India

Corresponding author: Dr. NA Bishurul Hafi, E-mail: bishuru@gmail.com

\begin{abstract}
Venereophobia is a relatively common but ignored diagnosis in our busy daily practice. Dermatologists encounter a lot of patients in their daily practice, presenting with different vague symptoms and self diagnoses related with genitals. Here we describe a case of a man with hypochondriasis of AIDS infection which prompted him for repeated testing and multiple consultations, only to be cured by proper counseling and initiation of psychotropics. We also report another case of genital herpes wrongly diagnosed repeatedly as venereophobia. These two cases have been described to highlight the double edged nature of the diagnosis. It lead to the conclusion that in most occasions even though the doctor provides the best diagnosis and treatment options, management is never complete without addressing his/ her concerns and fears. This may require a liaison clinic of psychodermatology.
\end{abstract}

Key words: Venereophobia; Psychodermatology; Hypochondriasis

\section{INTRODUCTION}

Venereophobia (VP) is defined as excessive and obsessive thoughts about sexually transmitted infections possibly triggered by single or multiple episodes of sexual encounters, not necessarily be intercourse proper. This is almost always seen in males which might be caused by hesitation of females driven by patriarchal society ethos. Though the case reports and trials about VP are very less in publication world it can be because of high level of ignorance of the entity among the treating physician barring him in diagnosing it accurately. Lack of liaison clinic set ups collaborating dermatology and psychiatry in most parts of the world may be another factor contributing to it. Since the interest on psychodermatology is still in unremarkable stage, comprehensive studies about VP are rarely published. This leads to half baked ideas about the entity and possible over generalization of the symptoms and misdiagnosis.

\section{CASE REPORTS}

\section{Case 1}

A 36-year-old government employee presented with a 10-year history of excessive worry that he may have acquired immunodeficiency syndrome (AIDS) after working in a health education program that involved reading several articles and websites about AIDS. Around that time, one of his neighbors died of AIDS, which made him more worried about having the disease himself despite not having a close relationship with that neighbor. He started attending local hospitals and asking to be tested for HIV infection after shaving or sharing cups with other people. He continued having himself tested repeatedly and contacting international labs in France and Germany, sending them his blood samples. He spent hours reading different articles about HIV testing and the HIV genome. He continued to send

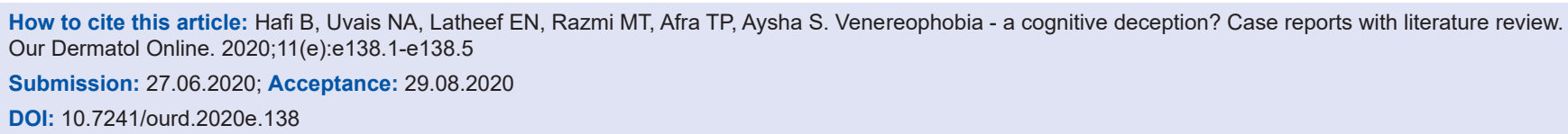


his blood for testing, around 100-200 times, despite getting negative results every time. He is aware that his excessive worries about having AIDS are irrational but cannot stop himself from sending his blood for testing; this has cost him lots of money, and he has had to borrow money from his wife and brothers. He was well dressed but appeared tearful and anxious, his speech was coherent, and he described his excessive fear of AIDS as irrational but was unable to resist being fearful. He had no abnormal perception, he believed that he had a psychiatric disorder, and he was seeking professional help. The patient was diagnosed with hypochondriasis, started on fluoxetine $20 \mathrm{mg}$ o.d., and was referred for cognitive behavioral therapy (CBT). He showed significant improvement of his symptoms and continued to attend CBT sessions.

\section{Case 2}

A 28 yr old NRI, regional manager of a MNC, visited OPD with asymptomatic erythematous papules on abdomen and trunk. While the clinical conclusion was of papular urticaria, he had some more stories to tell. He firmly believed this was due to some sexually transmitted infection he received from an extramarital relationship with a foreigner 2 years back. There were some lesions on penis one year back for which he had consulted a doctor abroad. He was treated with oral and topical antibiotics after ruling out infection by serological investigations of HIV, Syphilis and Herpes. He consulted another doctor after 6 months with a few papulo-pustules on pubic region which was treated in the line of folliculitis. He was also diagnosed with venereophobia for which counselling was offered. He presented to our OPD 6 months after this incidence and the diagnosis of venereophobia was reconfirmed after detailed history and clinical evaluation which showed nothing other than pearly penile papules. Serological investigations were not repeated to decrease economic burden and the previous test was done in very reliable laboratory. He was referred to psychodermatology clinic and detailed counseling was given. He was encouraged to have sex with his spouse, which he had stopped since the very first episode, and to resume his treatment for primary infertility. Though patient was relieved after the session, he still nurtured doubts in mind. After two months he came to OPD with a self investigation reports. To our surprise his anti HSV $2 \mathrm{IgG}$ antibody titre was high (65.09 RU/mL; $<16 \mathrm{RU} / \mathrm{mL}$ - negative). We repeated the test from another reputed laboratory and it again showed a high value of same (4.14 OD ratio; <0.90 ODR- negative).
Meanwhile his wife started mild burning sensation with superficial erosion on vulva and serology showed a high HSV 2 IgM antibody titre (3.22 OD ratio; <0.80 ODRnegative). She was treated with antiviral medications and detailed counseling was given for both.

\section{DISCUSSION}

Emergence of venereophobia can be paralleled to propaganda war against venereal diseases as mentioned by Rogerson in 1951 which is the earliest scientific opinion on the subject [1]. The effective campaign helped to create fear and there by seeking safe sex practices. But half information and misinformation led the growth of VP [2]. A study on effects of mass media publicity in AIDS panic by SD Soni, however, gave a different picture. Their findings suggested that, contrary to expectations, the referral rates of AIDS panic cases were highest in the earlier months when the level of media activity was low and decreased during the months following intense publicity about AIDS [3]. In a Chinese study, Deng et al. found out that a social excluding atmosphere to venereal patients and their relatives, influence of wrongful propaganda sheet and stimulation by harmful action and/or word of medical personnel were the 3 major social factors contributing to the development of VP [4]. It is interesting to note that there were a few voices of dissent on the scientific existence of VP as a syndrome as seen in an article by Mayou in 1975 [5].

Exact burden of the disease is not known since large scale studies have not been done yet. In an Indian study, venereophobia was seen in $13 \%$ of patients attending a psychosexual clinic [6.] It has been reported more in males. Mahajan BB has explained this trend as because of easy visibility of male genitalia, increased symptoms among males, paucity of female patients declaring sexual encounters [7]. However a recent study by Geeta et al., in a smaple size of 7859 (2631 females), mentioned VP among $2.11 \%$ of females, even though the details of presenting symptoms were not mentioned [8]. In another STD clinic based study on 497 patients VP was seen in $4.13 \%$ of females compared to $17.33 \%$ of males (p-0.0004) [9]. A study by Haritha et al. showed $4 \%$ prevalence of VP and all the patients were males [10]. In some studies on cutaneous manifestation among psychiatric patients venereophobia was seen in $1-4 \%[11,12]$. Whatever the prevalence may be, the psychological burden for the patient is real and a matter of concern. In a study by 
Wang et al., they have shown that in symptom check list (SCL)-90, the scores of somatization,obsessivecompulsive,interpersonal sensitivity,depression, anxiety ,phobic anxiety,paranoid ideation are obviously higher among VP patients than healthy people [13].

Modes of presentations: We are enlisting a few presentations described in detail in most of the previous articles in VP [7,14,15].

1. Spermatorrhea: This is defined as an involuntary discharge of semen, frequently following the act of defecation. Perhaps an indication of recent sexual activity and/or the presence of constipation, this symptom of occasional spermal losses cause great concern to the young male. In places like India, where lots of taboos and myths about sex prevails, it can result in development of dhat syndrome, in which patient will be excessively concerned about health issues of semen leakage [16]. Counselling and information providing remains the only treatment available for this condition but number of drop out is very high [17].

2. Pearly penile papules (PPP): Clinically, PPP appear as asymptomatic, multiple, smooth, dome-shaped, flesh colored papules localized circumferentially around the sulcus or corona of glans penis, significantly causing anxiety in teen and young even today [18]. The incidence is up to $48 \%$ and is more common in uncircumcised males in the second and third decades, although rarely it had been reported in younger age [19]. Its presence is not associated with sexual activity. They are known to persist throughout life but number may be decreased or even fade away with age or circumcision [20]. There is a recent case report of a patient having AIDS phobia led to schizophrenia like psychosis due to PPP [21]. It can be treated with ablation with cryotherapy, carbon dioxide laser, Nd YAG laser, pulsed dye laser, electrodessication with curettage, excisional surgery etc [22].

3. Sticky meatus: In the phobic patient, this sign is found to be the result of vigorous "milking" of the penis. Patient may carry out this operation while showing his penis to the physician. Symptoms such as burning micturition, dysuria, fever and signs of inflammation with or without inguinal adenopathy will indicate further work up for of sexually transmitted urethritis (Chlamydia). Sample from the sticky "discharge" is to be collected and urethral massage performed for collection if necessary. Smear for Gram staining and culture should be sent. In the case of venereophobia, pus cells will be absent and other serological tests negative

4. Threads in the urine: The phobic patient will examine anything that comes out of his urethra, leading to a close and careful examination of urine. If he had previous urethritis, gonococcal or nongonococcal he may discover threads in urine which are nothing but cloudy mucous fibers due to a change in the character of the lining of the penis brought about by the previous infection. Assurance should be given to the patient about non infectious nature of the condition.

5. Phosphaturia: This is usually reported by the patient as a milky discharge in the urinary stream, toward the end of the act of micturition. Differential diagnoses are increased consumption of milk and milk products,metabolic and hormonal causes such as parathyroid gland abnormality. When accompanied by dysuria, oliguria or anuria, referral to a urologist is warranted. Acetic acid test can be done bedside wherein adding a few drops of acetic acid to the urine sample leads to the disappearance of cloudiness

6. Hyperpigmentation of median raphe penis and scrotum

7. Fox Fordyce spots

8. Sebaceous hyperplesia

9. Smegma

10. Prominent veins

11. Bier's spots

12. Skin tag

13. Congenital and acquired melanocytic nevi

14. Angioma

15. Angiokeratoma

16. A single case of VP presenting as aquagenic pruritus has been reported [23].

There are some confusions regarding inclusion of AIDS or syphilis phobia in VP category. Every article on VP focus on normal physiological changes in external genitalia or genital symptoms with non STI causalities. But these germphobia of HIV/ HSV/ syphilis closely related with their previous sexual activities these also should be taken in to account for a comprehensive approach to VP since it itself can cause severe distress and even suicidal ideation [24]. Eg in cases of VP patients with PPP, even after getting rid of papules by lasers patients will not get cured of VP unless and until we address his concerns on infections. This reality has inspired John Todd and others to present AIDS as a Psychopathological theme highlighting the need of liaison clinics [25-27]. 


\section{LABORATORY EVALUATION}

It is always better to evaluate the patient with VP with relevant tests as the explaining the test reports itself is an important part of the treatment. It will give aid counselling to make him understand that he is normal. It is again important not to miss any diagnosis as we have discussed in the above case.

The following are the investigations recommended in a case of venereophobia:

1. Urine analysis

2. VDRL

3. HIV serology

4. Urethral and rectal swabs for Gram-staining and culture

5. Semen analysis.

Additional investigations:

1. Rectal swab, when history is indicative of MSM

2. Serology for HSV

3. Serology for Chlamydia trachomatis

4. Thyroid function tests (anxiety, sweating)

5. Electrocardiogram (palpitation)

6. Ultrasound scrotum for varicocele

7. Computed tomography/magnetic resonance imaging brain imaging for organic lesions (spermatorrhea)

8. Dermoscopic examination of PPP, atypical naevi, sebaceous hyperplasia

9. Skin biopsy (Fox-Fordyce, warts)

10. HPV typing for atypical skin tags.

The treatment of venerophobia is a challenging clinical situation. The primary task is psychoeducating the patient that the signs and symptoms he is experiencing are not part of an active venereal disease, which is often very difficult. A considerate and empathetic clinical encounter with the patient including repeated reassurances might be necessary and a diagnostic workup akin to an actual sexually transmitted disease is often required [28]. A detailed psychiatric evaluation is needed to understand the psychopathology better and a liaison approach provides significant improvement. ${ }^{[7]}$ Phenominologically it would be prudent to examine the symptom of venerophobia closely for proper management. Venerophobia can be hypochondriacal, obsessional or delusional and management should be tailored according to the psychopathology in individual patients. In hypochondriacal veneropobia, cognitive behavioural therapy, relaxation techniques like controlled breathing and visualisation and psychotropics (anti-anxiety agents and anti depressive agents) are the preferred modalities of treatment if conservative measures of counselling and repeated reassurances do not lead to improvement. When venerophobia presents as an obsessive fear, other obsessions and compulsions needs to be explored and the treatment consist of cognitive behavioural therapy, exposure and response prevention and psychotropics (selective serotonin reuptake inhibitors or clomipramine). In rare cases, venereophobia can present as a delusional belief. In such cases antipsychotic medications may be needed. Furthermore, co-morbid psychiatric disorders such as depression which is often found in patients with venerophobia also should be treated appropriately. In a study by Xia et al., alprazolam was found to have beneficial effect in decreasing anxiety among VP patients, even though there were no significant post treatment differences in phobia [29]. Psychiatric services should be provided in all venereology clinics [30].

\section{CONCLUSION}

The above case reports and the discussion highlight the importance of liaison clinics in dealing with such cases. Ignoring the gravity of the symptoms in busy OPDs may have profound negative effects on the patient and associated family. A detailed workup and minimal but comprehensive investigations should be done before labeling anyone with VP since missing the venereal diseases will be catastrophic.

\section{Consent}

The examination of the patient was conducted according to the principles of the Declaration of Helsinki.

The authors certify that they have obtained all appropriate patient consent forms, in which the patients gave their consent for images and other clinical information to be included in the journal. The patients understand that their names and initials will not be published and due effort will be made to conceal their identity, but that anonymity cannot be guaranteed.

\section{REFERENCES}

1. Rogerson HL. Venereophobia in the male. Br J Vener Dis. 1951;27:158-9.

2. Pedder JR. Psychiatric referral of patients in a venereal disease clinic. Brit J Vener Dis. 1970;46:54-7.

3. Soni SD, Windgassen E. AIDS panic; Effects of media publicity. Acta PsychiatricaScandinavica. 1991;84:121-4.

4. Yunhua D. Preliminary Analysis on the Social Factors Influencing Venereophobia. Medicine and Society. 2001;04:R-05. 
5. Mayou R. Psychological morbidity in a clinic for sexually transmitted disease. Sexually Transmitted Infections. 1975;51:57-60.

6. Verma KK, Khaitan BK, Singh OP. The frequency of sexual dysfunctions in patients attending a sex therapy clinic in North India. Arch Sex Behave 1998;27:309-14.

7. Mahajan BB, Shishank M. An approach to venereophobia in males. Indian J Sex Transm Dis AIDS. 2017; 38: 103-6.

8. Arakkal GK, Damarla SV, Kasetty HK, Chintagunta SR. Changing trends in sexually transmitted infection (STI) clinic attendees Current scenario. Int J Med Sci Public Health. 2014;3:1215-8.

9. Sarkar S, Shrimal A, Das J, Choudhury S. Pattern of sexually transmitted infections: a profile from a sexually transmitted infections clinic of a tertiary care hospital of eastern India. Ann Med Health Sci Res. 2013;3:206-9.

10. Thiruveedhula H, Chowdary KS, Rao GV, Galla SR. Sociodemographic, Clinical and Microbiological Study of Sexually Transmitted Infections in a Tertiary Care Hospital of South India. Int J Curr Microbiol App Sci. 2016;5: 674-9.

11. Shanmugasundaram V, Sunu J, Nithya D, Parimala M. "A study of cutaneous manifestations of patients with psychiatric disorder." Journal of Evolution of Medical and Dental Sciences. 2016;5:564-6.

12. Kuruvila M, Gahalaut P, Zacharia A. A study of skin disorders in patients with primary psychiatric conditions. Indian J Dermatol VenereolLeprol. 2004;70:292-5.

13. Wan-juan W, Hong-min L, Wen-yu G. Analysis on the Psychological State of Patients Suffered from Venereal Hypochondriasis. Chinese Medical Ethics. 2007;04:R395.

14. Agrawal SK, Bhattacharya SN, Singh N. Pearly penile papules: A review. Int J Dermatol. 2004;43:199-201.

15. Michajlowski I, Sobjanek M, Michajlowski J, Wlodarkiewicz A, Matuszewski M. Normal variants in patients consulted in the dermatology clinic for lesions of the male external genitalia. Cent European J Urol. 2012;65:17-20.

16. Mehta V, De A, Balachandran C. Dhat syndrome: a reappraisal. Indian J Dermatol. 2009;54:89-90.

17. Grover S, Gupta S, Avasthi A. A follow-up study of patients with Dhat syndrome: Treatment pattern, outcome, and reasons for dropout from treatment. Indian J Psychiatry. 2016;58:49-56.
18. Hogewoning CJ, Bleeker MC, van den Brule AJ, Voorhorst F, van Andel RE, Risse EK, et al. Pearly penile papules: still no reason for uneasiness. J Am Acad Dermatol. 2003;49:50-4.

19. Neri I, Bardazzi F, Raone B, Negosanti M, Patrizi A. Ectopic pearly penile papules: a paediatric case Genitourin Med. 1997;73:136.

20. Agha K, Alderson S, Samraj S, Merry C, Lee V, Patel R. Pearly penile papules regress in older patients and with circumcision. Int J STD AIDS. 2009;20:768-70.

21. Verma GK, Sharma DD, Sharma RC, Kumar S, Tegta GR, Negi AK. HIV/AIDS phobia leading to schizophrenia like psychosis in a benign cutaneous condition: pearly penile papules. Int J Health Sci Res. 2016; 6:356-9.

22. Sapra P, Sapra S, Singh A. Pearly Penile Papules: Effective Therapy With Pulsed Dye Laser. JAMA Dermatol. 2013;149:748-50.

23. Sekar CS, Srinivas CR, Jacob S. Aquagenic pruritus: beneath water "lies". Indian J Dermatol. 2011;56:446-7.

24. Kausch, Otto. Irrational fear of AIDS associated with suicidal behaviour. Journal of Psychiatric Practice. 2004;10:266-71.

25. Todd J. AIDS as a Current Psychopathological Theme: A Report on Five Heterosexual Patients. The Brritish Journal of Psychiatry. 1989;154:253-5.

26. Glass GF. AIDS phobia; a psychodynamic perspective. Journal of Gay and Lesbian Psychotherapy 1993;2:7-36.

27. Knapp S, Vandecreek L. Fear of AIDS: Its meaning and implications for clinical practice. J ContempPsychother. 1989;19:239.

28. Yong-hua X, Min L, Zhong-wei T. The controlled study of Psychological suggestion and Alprazolam on Venereophobia. Medical Journal of Chinese People's Health. 2008;23:R749.7.

29. Bhanji S, Mahony JD. The value of a psychiatric service within the venereal disease clinic. Sexually Transmitted Infections. 1978;54:266-8.

30. Chowdhry S, Jaiswal P, Souza PD, Dhali TP. VenereophobiaSexually Transmitted Disease. J Emerg Dis Virol. 2018;4:1-4.

Copyright by NA Bishurul Hafi, et al. This is an open access article distributed under the terms of the Creative Commons Attribution License, which permits unrestricted use, distribution, and reproduction in any medium, provided the original author and source are credited.

Source of Support: Nil, Conflict of Interest: None declared. 